\section{Intelligence of the crow.}

I find, by referring to my note-books, that I have witnessed several times the occurrence of crows breaking mussels by dropping them from considerable heights (ScIence, p. ö13). In one instance, I had my field-glass with me, and made careful notes of what took place. The crows had assembled on Duck Island, in the Delaware River, and were busily engaged in running along the edges of the sand-bars, exposed at low tide. Every few moments, one of them would rise up to a height of fully fifty feet, carrying a mussel in its beak, and, flying inland to a distance of one hundred yards, would let the mollusk fall on the meadow. Usually the force of the fall was sufficient to break the shell. 'The crows, as soon as they had let fall their burden, immediately returned to the island and bars, and gathered more mussels. This was continued until the returning tide made mussel-hunting impracticable. In no instance did the crows carry the food they were gathering by their feet. There is one fact with reference to this habit of the crows which is, I think, indicative of greater intelligence than the mere fact of lifting an object and dropping it in order to break it. This is, that all the mussels so dropped were left undisturbed until the returning waters made further fishing impracticable, when the birds hastened to feast on the results of their intelligent labor. Marvellous as it may seem, these crows recognized the nature of tides, and, knowing their time was short, made as good use of it as possible.

If any more striking evidence of intelligence on the part of birds can be produced, let it be placed on record forthwith.

C. C. Aвbotr.

\section{Impregnation in the turkey.}

An interesting fact respecting our domestic turkey has recently come to my notice. A friend, finding that a stray turkey had recently come upon his premises with the intention of remaining, finally shut it up in his chicken-yard, where it was permanently confined with no other associates than the chickens. The prisoner at once began to lay eggs, and, after a nest was formed, sat upon them, hatching out, in the usual time, nine healthy turkeys. Three others, that had been hatched by a hen, died soon for want of care. The eggs, thirteen in all, were laid without any connection with a turkey-cock. An impregnation, then, that must have taken place before the fowl was placed in confinement, must have answered for all the eggs. Agassiz states that one copulation is supposed to answer for more than one egg in the case of the turkey, but adds that the supposition needs confirmation. The facts here mentioned seem conclusive, as there was no possible way in which connection could have taken place after the turkey was confined.

Springfield, Mo.

THE GRAPE PHYLLOXERA IN FRANCE.

Compte rendu des travaux du service du Phylloxera. Année 1882. Procès verbaux de la session annuelle de la Commission supérieure du Phylloxera. Rapports et pièces annexes. Lois, décrets et arrêtés relatif au Phylloxera. Paris, Impr. nat., 1883. 603 p. $4^{\circ}$.

The Compte rendu des travaux du service du Phylloxera for the year 1882 , just received in this country, makes a large volume, contain- ing numerous reports of special committees and delegates. The Commission supérieure du Phylloxera, which consists of some thirt $y$-seven members, including such well-known investigators as Dumas, Pasteur, Tisserand, Cornu, Balbiani, Marion. Marès, with a number of deputies and senators, was convoked by the minister of agriculture on the 19th of January, 1883. The first sub-committee at the session of Jan. 22 submitted its report, which was accepted by the Commission supérieure. This report may be thus summed up:-

After having passed upon 185 proposed remedies, they were unable to award the prize of 300,000 francs offered by the government in 1874 , as they recognized in none of the new propositions any merit, whether as to novelty or more desirable methods of application of any insecticide already known. As in previous years, the substances most often recommended were salt, lime, soot, and cinders. It is well known that salt has produced nothing but bad effects on the vine, lime has amounted to little, while soot and cinders are but adjuncts to other modes of treatment. Among plants, Pyrethrum, tobacco, Quassia, and other similar products, are still urged by applicants for the prize, notwithstanding that the uselessness of such products has been shown by past experience. In fact, the proposed remedies range from dynamite and electricity to prayers and processions.

The second sub.committee reported through its chairman, M. Cornu, on the spread of the insect through France, the report being accompanied by a map which shows that nearly onehalf of France is infested with Phylloxera. The map indicates particularly (1) the 'arondissements' in which the presence of Phylloxera has not yet been observed, and into which it is forbidden to introduce any vines from phylloxerated districts or from foreign countries; (2) districts in which the insect occurs quite generally, but into which the introduction of foreign vines, or vines from other phylloxerated districts, is not authorized; and (3) badly infested districts, into which the introduction of foreign and French vines from phylloxerated districts is authorized. These last constitute nearly one-third of the area of France.

It will be well for those, who, allured by the liberal offer of the French government, venture to propose a Phylloxera remedy, to remember that one of the absolute conditions for the awarding of the prize is that the remedy shall be based on positive and authentic experience. A great many risionary and theoretical propo- 
sitions have been sent to us of late years with a request that we assist the proposers in presenting their claims to the French government. In almost erery instance the proposers have shown an absolute lack of experience, both as to the insect and as to the methods they recommend.

The question of the winter egg, so called, has again occupied much of the attention of the commission, which places great confidence in the researches in regard to it of one of its eminent members, Balbiani, who has been instructed to continue his investigations. In reference to this egg, and the importance of destroying it, there has, of late, been much discussion in France; and we may repeat our answer to the following question, recently put to us by one of the first French investigators into the life-history of Phylloxera :-

"L'oeuf soi-disant d'hiver de M. Balbiani est-il indispensable à la reproduction du Phylloxera, ou bien la reproduction agame vous parait-elle possible durant plusieur's années ou "même indéfiniment?"

Our reply was, that the impregnated egg (we prefer this term to 'winter egg') is indispensable to the continued reproduction of Phylloxera, and that normally it is produced annually in the cycle of the insect's life; but that agamic multiplication may, under favoring conditions. extend to the third or fourth year, and, for aught we know, longer.

In reading over Targioni-Tozzetti's criticism of Balbiani, and the latter's reply, in late numbers of the Comptes rendus de l'académie, we felt, that, so far as our own observations and experiments have gone, both were in a degree right, and both wrong. There is no question but that Balbiani is essentially right in his conclusion as to the necessity for the impregnated egg at some period during the annual derelopment, under the conditions of our changing seasons. All the facts ascertained, as well as all analogy from what is known of the lifehistory of other species of the family, point to the accuracy of that conclusion. Yet experiments enough are on record to show, that, where the conditions of early spring and sum- mer are artificially maintained, agamic reproduction in aphides may be greatly extended, and even go on to the third or fourth year.

Of course, this possibility of such continued agamic multiplication does not change the practical fact of what does take place in an ordinary year under ordinary seasonal changes. Balbiani, therefore, is theoretically quite right in insisting on the importance of the destruction of his winter egg. Just here, howerer, is where we shall have to differ from him as to the practical value of attempts to do so, and for the following reasons :-

It is a universally conceded fact, that the species hibernates chiefly in the dormant larval state underground. Now, even supposing that every so-called winter egg could be destroyed, we know positively that the vines would still be infested, and that new impregnated eggs would again occur the ensuing fall or winter. Therefore, even on Balbiani's belief, these eggs would have to be annihilated for at least two consecutive years to do any good. But, unfortunately, all methods of annihilation heretofore proposed have proved impracticable, and, in fact, impossible. ${ }^{1}$ Decortication must always be but partially successful, as the eggs are not confined to the loose bark or to the older portions of the vines. Moreover, our researches in this country (and it seems to us that experience in Europe corroborates them) show conclusively that this impregnated egg is not necessarily a winter egg, for it is extremely rare, and difficult to discover, during winter, or at any time: hence, and for the reason that larval hibernation prevails, we are justified in one or the other of the following conclusions :-

$1^{\circ}$. That the sexual females do not necessarily confine the impregnated egg to the stems and branches, but lay them also at the base of the vine, or even beneath the ground; $2^{\circ}$. That hypogean, apterous females also produce the sexed individuals underground; $3^{\circ}$. That the impregnated egg hatches the same season that it is laid.

Now, there are certain facts of experience that would give some warrant to all three of these conclusions, the first and second being fully justified by facts recorded by Balbiani and ourselves. The third statement we have proved true with Phylloxera Rileyi ; and M. P. Graels has also proved it for $P$. vastatrix in Spain (see Amer. nat., 1881, p. 483).

Thus we have little faith in the results of decortication; and we have already expressed much the same views in the American naturalist, in our eighth Missouri report, and in our report to the Department of agriculture for 1878, p. 83.

With regard to the use of American vines as stocks on which to graft the more susceptible French vines, the commission admits the success of the former in rich or deep soils, but concludes that they leave something yet to be

\footnotetext{
1 The eggs, in the rare cases where they are found, are concealed as much as possible in minute cracks and crevices, so that mechanical decortication cannot well reach them all; while the application of heat, as by torches, would not destroy them all unless intense enough to injure the vines.
} 
desired on light or superficial soils. It seems to us that this amounts to little more than saying that a vigorous vine cannot be grown on a poor soil ; the fact being that the American vines for this particular purpose have made their way against much opposition, and remain to-day the best solution, all things considered, of the Phylloxera question.

'The commission finally concluded that the prize of 300,000 francs be still reserved, but maintained. It seems to us that some disposition should be made of this prize, as the commission must not expect to get any more satisfactory means of dealing with the pest than those already proposed, that are based on experience and sound scientific principles. $\mathrm{By}$ this we mean that the treatment of any such underground pest that has so raried a life-history must necessarily involve a given amount of time, money, and labor, regardless of the particular substance or means employed ; and to look for a ' remedy' that shall involve neither is to look for the impossible, - the miraculous. Those who were the first to suggest and prove the value of resistant American vines, those who established the value of submersion and bisulphide of carbon, and those who have helped toward a sound knowledge of the insect's life-history, - all deserve recognition.

The methods recommended by the commission for the year 1883, aside from the use of the American vines, are the old ones of submersion, bisulphide of carbon, and sulphocarbonate of potassium.

C. V. RILey.

\section{CALIFORNIA AGRICULTURE.}

University of California. College of agriculture. Report of the professor in charge to the president, being a part of the report of the regents of the university. 1882. Sacramento, State, 1883. 179 p. $8^{\circ}$.

THis report includes the general report of the professor in charge, E. W. Hilgard, to the president, and four appendices, or special reports : viz., report and discussion of work in the agricultural laboratory, by E. W. Hilgard ; report on instruction given, and culture experiments, by Charles H. Dwinelle; report of W. G. Klee, gardener in charge of the experimental grounds, on fruit and miscellaneous cultures ; report of work done in the viticultural laboratory, with record and discussion of results, by F. W. Morse.

In his general report, Professor Hilgard reiterates the opinion which he has advanced in another publication (Atlantic monthly, April and May, 1882), that, in view of the present wide-spread indifference to agricultural education, " the work of an experiment-station . . . is the key to the situation, so far as the utility and public appreciation of the College of agriculture is concerned." In accordance with this view, work appropriate to an experimentstation has been carried on, in addition to the work of instruction, to as great an extent as the time and means at command permitted; and the four appendices to the general report contain the results of the investigations which have been made.

The work of the agricultural laboratory has consisted chiefly of an examination of the more important and widely distributed soils of the state. These are classified geographically ; and chemical and mechanical analyses of several representative samples of each class have been made, from the results of which very important conclusions are drawn as to the present and prospective value and the proper treatment of these soils. Professor Hilgard is far from falling into the old erroneous belief that chemical analysis can be depended upon to show the immediate deficiencies of a soil ; but he holds that it may furnish important information as to the amount and kind of reserve matters which it contains, and afford a guide to a rational method of cultivation; and in his hands it certainly seems to justify the claims made for it.

One of the most interesting portions of the horticultural report in appendix III. is that devoted to the vineyard, where are given the results of experiments on grafting the European grape (Vitis vinifera) upon a native Californian species (Vitis californica). The conclusion is reached, that " it must be considered definitely proved that the Vitis californica is well adapted as a grafting stock for a large number of the varieties of Vitis vinifera." The importance of this fact, of course, lies in the greater power of resistance to Phylloxera possessed by the American species. Experiments upon the latter point are now in progress with grafted specimens.

The account of the viticultural work includes some observations on the occurrence and development of Phylloxera, but is chiefly occupied with the results of the experiments on wine-making, which, though still incomplete, and though necessarily executed on a small scale, furnish much valuable information as to the character of the wine to be obtained from different varieties of grapes, and from grapes grown in different regions of the state. They can hardly fail, if continued, to exert a most 